\title{
Social work in health - The way ahead
}

\author{
Gregory Winkelmann LlB, MSW, MANZASW
}

Gregory Winkelmann is a surgical social worker at Middlemore Hospital

\section{Abstract}

In this opinion piece the challenges facing social workers working in the physical and mental health fields are outlined. These challenges include the growing emphasis on the more holistic approach to treatment that is gaining emphasis with the waning of the medical model, the application of te Tiriti o Waitangi to how we practise and the integration of bi-culturalism and multiculturalism into practice, and a greater emphasis on recovery and empowerment. The piece goes on to suggest how these challenges can be faced using an evidence-informed practice and interventions in a culturally and Treaty-responsive pathway.

It is clear that the treatment of those with either a physical or mental illness is moving away from the medication-centred model (Doel \& Shardlow 2009). I see an increasingly important role for social workers as part of the Medical Diagnosis and Treatment (MDT) both in the community and in in-patient units. Social workers are in a unique position to have an overview of a service user's life and the psycho-social factors that contribute to their becoming unwell. Because of this they are also in a unique position to contribute significantly to a service user's recovery.

To some extent addressing the question of priorities and challenges that the changing role of social work will necessarily bring resists an easy answer. Just like the factors that lead to illness itself, the various factors that stand out to me as important to the social worker's role in treating illness are intertwined and interdependent. I see the priority areas for social workers over the next several years as centred on taking the initiative in addressing the over-representation of Maori in negative health statistics, the promotion of the profession's involvement in a patient's care in a non-medication-centred environment and meeting the challenges that this increasing involvement will necessarily bring. Those challenges will be, firstly, finding a model of treatment and providing a service that reflects the bicultural/ multicultural nature of New Zealand society and specifically the needs of tangata whenua, secondly, interacting with service users in a proactive rather than reactive way and, thirdly, endeavouring to ensure that interactions with service users are not disempowering but actually promote the service users' control of their own lives. Above all, though, I think the principle challenge is going to be ensuring that we, as a profession, practise in a manner based on or informed by evidence rather than just gut instinct.

\section{Cultural imperatives}

Te Tiriti o Waitangi in general and Te Puawaitanga and Raranga Tupuake (Ministry of Health 2006) in particular mandate ensuring accessible and appropriate health services for Maori. For 
services to be accessible and appropriate they need to be sensitive to the culturally specific needs of Maori. For this to happen in our profession there needs to be a greater emphasis on the recruitment and retention of Maori social workers and a greater emphasis on culturally specific training for all staff. There needs to be a shift of emphasis from treatment of the individual in isolation to treatment of the individual as part of a collective - whanau, hapu and iwi (Ministry of Health 2002).

Application of the principles of Te Tiriti o Waitangi and of the Pacific and Maori models of health care should not be restricted to those of Maori or Pacific ethnicity. In my opinion, both the treaty and the health models describe the essential facets of what would be an ideal system of health; a system that is holistic and that is achievable. The treaty mandates partnership, protection and participation (ibid). As social workers we can ensure that patients are fully informed of their care plan and have input into it. We can ensure that their voices are heard in the MDT. Because both Pacific and Maori models of health care place equal emphasis on all domains of a person's life, their application ensures that a holistic approach is taken and that aspects are examined other than the presenting complaint that may be wholly or partially causative of that complaint.

\section{Proactive}

In my time as a mental health and medical social worker, both myself and, I have noticed, my fellow professionals have assisted service users to deal with the day-to-day exigencies of life. Problems such as benefit issues, discharge accommodation, debt repayments and the like are dealt with as they arise. They tend to be dealt with as, if you like, fires that need to be put out. In my experience, and this is probably more true of in-patient units, this type of work takes up pretty much all of the social worker's day. Such problems are extremely important to service users and I do not underestimate the importance of solving them. I do not, however, believe that social workers are uniquely qualified to provide the solutions. I believe that social workers are uniquely qualified to bring a holistic overview to the treatment of patients. I believe that their skills in group work, strengths-based assessment and interventions, motivational interviewing and the practice of trauma informed care would be best utilised in the assessment framework outlined previously. The assessment process will often bring to light problems that do not present themselves as fires that need to be put out, but they are problems that are fundamental to the patient's wellbeing and recovery. But to have the time to do this effectively, we as a profession need to be at least partially relieved of the task of helping the patient solve some of the more pressing but more superficial problems of day-to-day life. While working alongside a patient to solve these problems can enhance the therapeutic relationship and be used to increase the patient's empowerment, performing tasks on behalf of a patient without the patient's involvement, which is often necessary, is of no value in that regard. Too often, being required to provide this type of intervention may also, over time, operate to 'de-skill' practitioners by depriving them of the opportunity to put learned theory into practice.

\section{Empowerment}

I sometimes thought, when I saw a young patient battling their way through the mental health system, that, when they reached middle age, they would not be grateful for some of the assistance that mental health services had provided them in their younger years. There 
is a danger for mental health professionals to fall into the trap of generalisation and view all patients as being wholly incapable of looking after themselves. They begin to work for rather than work with the patient. The patient becomes equally convinced of their incapability and increasingly becomes reliant on both community and in-patient service workers to function in their daily lives. In the course of my Doctoral research and homeless volunteer work I have seen at first hand the loss of confidence and motivation that can result from this type of approach. Sure, there are some patients that are so unwell that they simply cannot really look after themselves in any way. But I think that this is rare. What is required is a strengths-based and task-centred approach to interactions with patients, including the heavy involvement of whanau and friends. It would start with easily achievable tasks, with assistance as necessary - and plenty of encouragement, building the degree of difficulty and lessening the degree of assistance as confidence increases. This approach will, I feel, assist the patient in understanding that they have a future and that it is theirs to shape. Seeing the patient as a human being with potential as opposed to a set of problems and symptoms, and assisting the service user to see themselves in this light as well, will make for better long-term outcomes for service users and less repeat business for us.

\section{Evidence-based practice}

In social work, evidence-based practice is a process involving creating an answerable question based on patient need, locating the best available evidence to answer the question, evaluating the quality of the evidence as well as its applicability, applying the evidence, and evaluating the effectiveness and efficiency of the solution. There continues to be discussion among both social work academics and professionals as to whether an evidence approach is desirable (Mason 2011). However, it seems to me that a consensus is beginning to emerge that evidence-based practice should involve a process in which the practitioner combines well-researched interventions with clinical experience, ethics, client preferences, and culture to guide and inform the delivery of treatments and services. The key words here are 'guide' and 'inform'. Interventions used should be consistent with, but not necessarily the same as, theories models and interventions that have been shown, through research, to produce good client outcomes. In other words, '...the integration of the best research evidence with clinical expertise and patient values' (Sackett, Straus, Richardson, Rosenberg, \& Haynes 2000). Or, to put it another way, a basis of research evidence is necessary, but not sufficient, for effective social work practice. It is tolerably clear that this integrated approach works (Drisko \& Grady 2012) Thus, I think that a priority for any service should be improving social workers' access to the evidence that is available through increased training in the efficacy and utilisation of specific models and interventions, and training on how to access databases of evidence electronically.

\section{Model of treatment}

My ideal pathway for a patient moving through the mental and physical health systems would involve the application of a psycho-social assessment as soon as possible. This assessment would involve establishing the degree of well being in the various domains of a patient's life. Ideally this assessment tool would be based on the Maori and Pacific Island health models of te whare tapa wha and fonofale, with their equal emphasis on all domains of a person's life and, in particular, their de-emphasis of the individual as a discrete and unaffected entity and their recognition of the importance of the family, social and cultural 
domains. The theory underpinning the assessment tool would be strengths based and focused on community and whanau/aiga. Once completed, the results of the assessment would be discussed with the patient and family if appropriate and a plan devised to achieve any goals that the service user may have. A record of the assessment results, the patient's goals and any progress made towards meeting those goals would follow the service user throughout his or her involvement with the service. It would be a living document and, therefore, adapted and changed in keeping with changes in the patient's life.

\section{Summary}

Our profession needs to set priorities to reflect the changing mental health and physical illness treatment paradigm and meet the challenges that arise as a consequence. Those priorities must necessarily be framed to meet the increasing emphasis on a multicultural, holistic and strengths-based approach to mental health in New Zealand. The challenges must be met in a professional manner based on best evidence.

\section{References}

Doel, M., \& Shardlow, S.M. (Eds.). (2009). Educating professionals: Practice learning in health and social care (pp. xxviii + 294). Farnham: Ashgate.

Drisko, J., \& Grady. M. (2012). Evidence-based practice in clinical social work. Springer Verlag: New York.

Mason, S.E. (2011). Another look at evidence-based practice: On emphasizing viability and ethics. Families in Society 92(3): 245-246.

Ministry of Health. (2006). Raranga Tuapuke: The Māori Health Workforce Development PLan 2006. Wellington: Ministry of Health.

Ministry of Health. (2002). He korowai oranga: Māori health strategy. Ministry of Health: Wellington.

Sackett, D. L., Straus, S. E., Richardson, W. S., Rosenberg, W., \& Haynes, R. B. (2000). Evidence-based medicine: How to practise and teach EBM. Churchill Livingstone: Edinburgh. 